RESEARCH REPORT

\title{
Seasonal variation of sudden infant death syndrome in Hawaii
}

\section{David T Mage}

Correspondence to: Dr D T Mage, Temple University, Institute for Survey Research, 1601 North Broad Street, Suite 502, Philadelphia, PA 19122-6099, USA; david.mage@temple.edu

Accepted for publication 12 March 2004

\begin{abstract}
Objective: To test whether the sudden infant death syndrome (SIDS) rate displays the universal winter maximum and summer minimum in Hawaii where there is no appreciable seasonal variation of temperature.

Design: The null hypothesis is tested that there is no seasonal variation of necropsied SIDS in Hawaii. The numbers of live births and SIDS cases by month for the years 1979 to 2002 were collected and the monthly SIDS distribution is predicted based on the age at death distribution.

Setting: The state of Hawaii, located in the midst of the Pacific Ocean, has a semi-tropical climate with temperatures fluctuating diurnally as $25 \pm 5^{\circ} \mathrm{C}$ throughout the year. Therefore homes are unheated and infants are not excessively swaddled. The Hawaii State Department of Health maintains vital statistics of all infant births and deaths.

Main results: The results reject the null hypothesis of no seasonal variation of SIDS $(p=0.026)$. An explanation for the seasonal effect of the winter maximum and summer minimum for Hawaiian SIDS is that it arises from the cycle of the school session and summer vacation periods that represent variable intensity of a possible viral infection vector. SIDS rates in both Hawaii and the United States increase with parity, also indicating a possible role of school age siblings as carriers.

Conclusions: The winter peak of the SIDS in Hawaii is support for the hypothesis that a low grade viral infection, insufficient by itself to be a visible cause of death at necropsy, may be implicated as contributing to SIDS in vulnerable infants.
\end{abstract}

S udden infant death syndrome (SIDS, 9th International Classification of Diseases 798.0, 10th International Classification of Diseases R95) is a diagnosis used when a thorough necropsy and death scene investigation provide no apparent cause of a sudden and unexpected death in an infant or young child. SIDS has three underlying global characteristics found in virtually all studies: an age distribution sparing infants at birth, rising to a maximum rate at two months of life (63 days) and falling rapidly and approaching zero at one year ${ }^{1}$; a gender distribution with a $50 \%$ male excess $^{2}$; and a seasonal distribution with rate maximums in the winter and rate minimums in the summer in both the northern and southern hemispheres. ${ }^{34}$ This seasonal variation of SIDS has been associated not only with cold weather, ${ }^{5-7}$ paradoxical overheating by excess swaddling, ${ }^{8}$ and air pollution, ${ }^{9}{ }^{10}$ but with respiratory infection corresponding to the school year cycle, ${ }^{11-14}$ which all have maximum effect in the winter and minimum effect in the summer. Guntheroth et al $^{14}$ concluded that "the seasonality of sudden infant death syndrome is related to the seasonality of respiratory infections and that the seasonality is influenced by respiratory infections being spread from school children to infants during periods when schools are in session." The occurrence of SIDS in Hawaii, a state with no appreciable seasonal temperature variation, provides an opportunity to control for the influence of seasonal temperature changes on rates of SIDS. The seasonal relations of SIDS in Hawaii were first investigated in $1984,{ }^{13}$ and again in 1995 in a preliminary study for this paper. ${ }^{15}$

The state of Hawaii is located in the midst of the Pacific Ocean (Honolulu is at $21^{\circ} 20^{\prime}$ north latitude) and has a semitropical climate. The average temperature ranges vary slightly throughout the year, cycling from about $20^{\circ} \mathrm{C}$ at night to about $30^{\circ} \mathrm{C}$ during the day. ${ }^{16}$ In December 2003 the average low temperature was $20^{\circ} \mathrm{C}$ but lower night time temperatures occur, with a December record low of $14^{\circ} \mathrm{C}$ in 1983 . Hawaii is therefore an ideal location to test the null hypothesis that there is no seasonal variation of SIDS when there is no appreciable seasonal variation from very low winter temperatures to very high summer temperatures.

\section{METHODS}

Available data for all 388 SIDS in Hawaii by necropsy status (four did not have a necropsy), age, gender, and date of death during the 24 year period 1979-2002 were provided by the Hawaii State Department of Health to obtain the seasonal age distributions and totals of monthly live births and SIDS. The expected number of births per calendar month is not a nominal one 12th of the annual total of births because of the variable number of days per month and a seasonal variation in birth rate. A convolution calculation is therefore required to estimate the expected numbers of SIDS in each month from the monthly birth rates and age distribution of SIDS. Table 1 shows the total numbers of Hawaiian births in each calendar month for the 24 year period from 1979 to 2002 . The expected numbers of deaths in each month are then predicted using the SIDS age distribution in Hawaii. Table 2 shows the age distributions of SIDS during the school year and summer vacation are similar.

An infant born in December who dies at an age of less than 1 month can die in December or January and an infant born in November who dies at an age between 1 and 2 months can also die in December or January. However, for simplicity, we assume that all SIDS predicted to die at an age less than 1 month would occur in the month of birth, SIDS occurring between 1 and 2 months of life would occur in the month after the birth month, etc. A preliminary analysis showed

Abbreviations: SIDS, sudden infant death syndrome; URI, upper respiratory infection 
Table 1 Hawaiian live births and necropsy confirmed SIDS, by calendar month, 19792002 , with predicted deaths computed by assuming no seasonal variation and a sinusoidal seasonal variation of death rate

\begin{tabular}{lllll}
\hline Lonth & Live births & $\begin{array}{l}\text { Expected SIDS by age } \\
\text { distribution at death, } \\
\text { 1979-2002, for no } \\
\text { seasonal variation }\end{array}$ & $\begin{array}{l}\text { Expected SIDS by cosine } \\
\text { function model fit to observed } \\
\text { SIDS 1979-2002* }\end{array}$ \\
\hline January & 37144 & 41 & 32.64 & 39.74 \\
February & 34710 & 43 & 32.29 & 36.21 \\
March & 36617 & 35 & 31.76 & 37.89 \\
April & 35945 & 42 & 31.58 & 33.49 \\
May & 36708 & 23 & 31.40 & 30.78 \\
June & 35580 & 24 & 31.42 & 26.55 \\
July & 37294 & 24 & 31.32 & 25.48 \\
August & 38045 & 27 & 31.57 & 25.46 \\
September & 39105 & 33 & 32.04 & 30.48 \\
October & 38719 & 31 & 32.54 & 33.40 \\
November & 36848 & 31 & 32.78 & 37.82 \\
December & 37984 & 30 & 32.63 & 384 \\
Total & 444699 & 384 & 384 & $\begin{array}{l}\text { 1979-2002 } \\
\text { *Observed monthly SIDS data modelled as } 0.810+0.241[1+\text { cosine } 2 \pi(t-30) / 365.25] .\end{array}$ \\
\hline
\end{tabular}

that assuming all infants dying at age less than 1 month were occurring in the month after the month of birth, etc, provides a negligible change in the expected number of SIDS in any given month. ${ }^{15}$

Given the total of 384 necropsied SIDS and the 1979-2002 total of 444699 live births, the procedure chosen to estimate the expected monthly number of cases from monthly birth totals if there is no seasonal variation is as follows: from table 1, there were 37984 births in December, and from Table 2, showing the age distribution of SIDS, we expect that the fraction of children dying of SIDS in December who were born in December is 0.075 . The contribution to the expected number of SIDS in December from children born in December is

$2.46=384$ (37 984/444 699) (0.075), where:

$384=$ total numbers of SIDS in Hawaii during 1979-2002;

$37984 / 444699=$ probability that a SIDS infant was born in December;

$0.075=$ probability that an infant born in December who dies of SIDS died in December.

This computation is repeated for the November birth cohort of 36848 infants using the 1-2 month fraction of 0.260 to estimate the number born in November and dying in December, as

$8.28=384(36948 / 444699)(0.260)$, and likewise for the other 10 months.

For evaluation of the alternate hypothesis that SIDS is related to an infection vector that varies seasonally with the school year, the Hawaii State Department of Education provided the starting dates of the school years (range 1 to 5 September) and the last days of school for each year (range 7-9 June), which makes the summer vacation period slightly different than the period from 1 June 31 August we defined as summer for our seasonal analysis. A small number of rural schools in Hawaii have recently shifted to a "multi-tract" system of school year round with shorter breaks in between rather than the traditional long summer break but this effect is considered negligible for the analysis. By reference to the date of each SIDS we calculated the number of SIDS during the summer vacation and during the rest of the year when school was in session for comparison with the expectation for that period.

Statistical analyses of these data for seasonality were performed using the Yates's $\chi^{2}$ test and the Edwards' test for a sinusoidal cycle of independent events. ${ }^{17}$ The Edwards' test is equivalent to placing a point for each calendar date of death about the rim of a circle corresponding to time intervals from 0 to 365.25 days. In the absence of any cyclic trend the centre of gravity of the data points will be at the centre of the circle, and will have a determinate sampling distribution. The distance from the centre has a test statistic equal to $-2 \ln p$, which is a basis for rejecting a seasonal variation. The ray from the centre of the circle through the centroid of the data hits the rim at the point of peak incidence.

\section{RESULTS}

In Hawaii the age distribution of SIDS and the $\sim 50 \%$ male excess of SIDS are similar to those throughout the continental United States and rest of the world, with a maximum rate at a completed two months of life and a 50\% excess of male SIDS. ${ }^{13}$ Adding new data to the 95 male and 58 female SIDS reported from 1974 to $1982,{ }^{13}$ there were 130 male and 106 female cases from 1983 to $1998,{ }^{18}$ and 15 male and 9 female cases from 1999 to 2002 reported by Hawaii State Department of Health. This pronounced decrease in the SIDS rate is probably related to the adoption of the supine position for infant sleep after warning that prone sleep is the central contributory cause for SIDS. ${ }^{19}$ The totals of 240 male and 173 female SIDS, with a 6\% male excess birth rate in Hawaii, represent a $31 \%$ male excess, which is not statistically different from an expected $50 \%$ male excess rate by a Yates's $\chi^{2}$ test $(\mathrm{p}=0.19){ }^{2}$

The total numbers of live births and the observed and expected numbers of necropsy confirmed SIDS cases from 1979 to 2002 are shown in table 1 for each month of the year. There were 11 early June cases before the end of the school year and nine early September cases at the end of the summer vacation, so a conservative approximation of the total numbers of observed and expected SIDS in the summer vacation period is the observed and expected totals for all of June through August. This procedure of dividing the year into summer (June-August) and non-summer (September-May) was originally suggested for testing for seasonality of hospital admissions for psychoses. $^{20}$ Seventy five SIDS occurred during June to August with an expected 94.31, and 309 SIDS were observed September to May with an expected 289.69. A Yates's $\chi^{2}$ test rejects the null hypothesis of no seasonal variation of SIDS $(p=0.026)$. This result occurred during a period when the preferred sleep position had shifted from prone to supine, and while necropsy standards have become more rigorous. Despite such changes, the results confirm the earlier finding of a summer minimum for years 1974-1978 when prone sleep position was not contraindicated. There were then 11 summer and 55 non-summer 
Table 2 Age distributions of SIDS during summer vacation and school year in Hawaii, 1979-2002

\begin{tabular}{|c|c|c|c|c|c|c|}
\hline \multirow[b]{2}{*}{$\begin{array}{l}\text { Monthly age interval of } \\
\text { the death by SIDS }\end{array}$} & \multicolumn{3}{|c|}{ Numbers of SIDS cases } & \multicolumn{3}{|c|}{ Fractions of SIDS by monthly age at death (number/total) } \\
\hline & $\begin{array}{l}\text { Summer school } \\
\text { vacation }\end{array}$ & $\begin{array}{l}\text { Non-summer } \\
\text { school year }\end{array}$ & Annual total & $\begin{array}{l}\text { Summer school } \\
\text { vacation }\end{array}$ & $\begin{array}{l}\text { Non-summer } \\
\text { school year }\end{array}$ & Annual total \\
\hline $0-1$ (0 to 30 days) & 9 & 20 & 29 & 0.123 & 0.063 & 0.075 \\
\hline $1-2$ & 15 & 86 & 101 & 0.205 & 0.273 & 0.260 \\
\hline $2-3$ & 15 & 69 & 84 & 0.205 & 0.219 & 0.216 \\
\hline $3-4$ & 12 & 55 & 67 & 0.164 & 0.175 & 0.172 \\
\hline $4-5$ & 5 & 37 & 42 & 0.069 & 0.117 & 0.108 \\
\hline $5-6$ & 5 & 20 & 25 & 0.069 & 0.063 & 0.064 \\
\hline $6-7$ & 6 & 14 & 20 & 0.082 & 0.044 & 0.052 \\
\hline $7-8$ & 4 & 2 & 6 & 0.055 & 0.006 & 0.015 \\
\hline $8-9$ & 0 & 6 & 6 & - & 0.019 & 0.015 \\
\hline $9-10$ & 1 & 3 & 4 & 0.014 & 0.010 & 0.010 \\
\hline $10-11$ & 1 & 1 & 2 & 0.014 & 0.003 & 0.005 \\
\hline $11-12$ & 0 & 1 & 1 & - & 0.003 & 0.003 \\
\hline $12-13$ & 0 & 0 & 0 & - & - & - \\
\hline $13-14$ & 0 & 0 & 0 & - & - & - \\
\hline $14-15$ & 0 & 1 & 1 & - & 0.003 & 0.003 \\
\hline Total & 73 & $315^{*}$ & 388 & 1.000 & 1.000 & 1.000 \\
\hline
\end{tabular}

SIDS, ${ }^{13} 15$ which suggests the sleep position does not contribute to the seasonal variability in death rate. These results support the conclusions of others ${ }^{11-14}$ that the school session-school vacation cycle may be a contributing factor for the observed seasonality of SIDS.

The Edwards' test $\mathrm{t}^{17}$ for an annual cycle with a single peak and a single trough as fit by a cosine wave was also used. Following the procedure, using the exact numbers of days in each month (31 January, 28.25 February, ...) the test statistic of 11.06 was found, which is equal to $-2 \log p$, where $p=0.004$. Thus the null hypothesis is rejected and the data are consistent with a seasonality of SIDS. The peak incidence was found at 31 days, corresponding to 31 January at 11:59 p.m.

In a related manner, we let an average year consist of 365.25 days so that an annual cycle can be modelled by equation 1 .

$$
\mathrm{pS}(\mathrm{t})=\mathrm{A}+\mathrm{B}[1+\operatorname{cosine} 2 \pi(\mathrm{t}-\phi) / 365.25]
$$

where $\mathrm{pS}(\mathrm{t})=$ rate of SIDS at time $\mathrm{t}: 0<\mathrm{t}<365.25$,

$\mathrm{A}=\mathrm{a}$ constant rate of SIDS from non-seasonal causes,

$\mathrm{B}=$ the average of the variable rate of SIDS from seasonal causes,

$\phi=$ the time of maximum SIDS in the annual cycle, and

$\mathrm{pS}(\mathrm{t}) \mathrm{dt}=$ probability of a SIDS occurring between time $\mathrm{t}$ and time $\mathrm{t}+\mathrm{dt}$.

Integrating equation 1 , as $\mathrm{pS}(\mathrm{t}) \mathrm{dt}$ we can obtain an expression for the monthly expectations accounting for variable numbers of days in the monthly data, as equation 2 .

$$
\begin{aligned}
\mathrm{S}(\mathrm{T} 2)-\mathrm{S}(\mathrm{T} 1)= & (\mathrm{A}+\mathrm{B})(\mathrm{T} 2-\mathrm{T} 1)+ \\
& {[\mathrm{B} 365.25 / 2 \pi][\sin (2 \pi[\mathrm{T} 2-\phi]} \\
& / 365.25)-\sin (2 \pi[\mathrm{T} 1-\phi] \\
& / 365.25)]
\end{aligned}
$$

where $\mathrm{Tl}$ is the start of a month (for example, $\mathrm{Tl}=0$ at 12 01 am on 1 January)

T2 is the end of that month (for example, T2 = 31 at 1159 pm on 31 January)

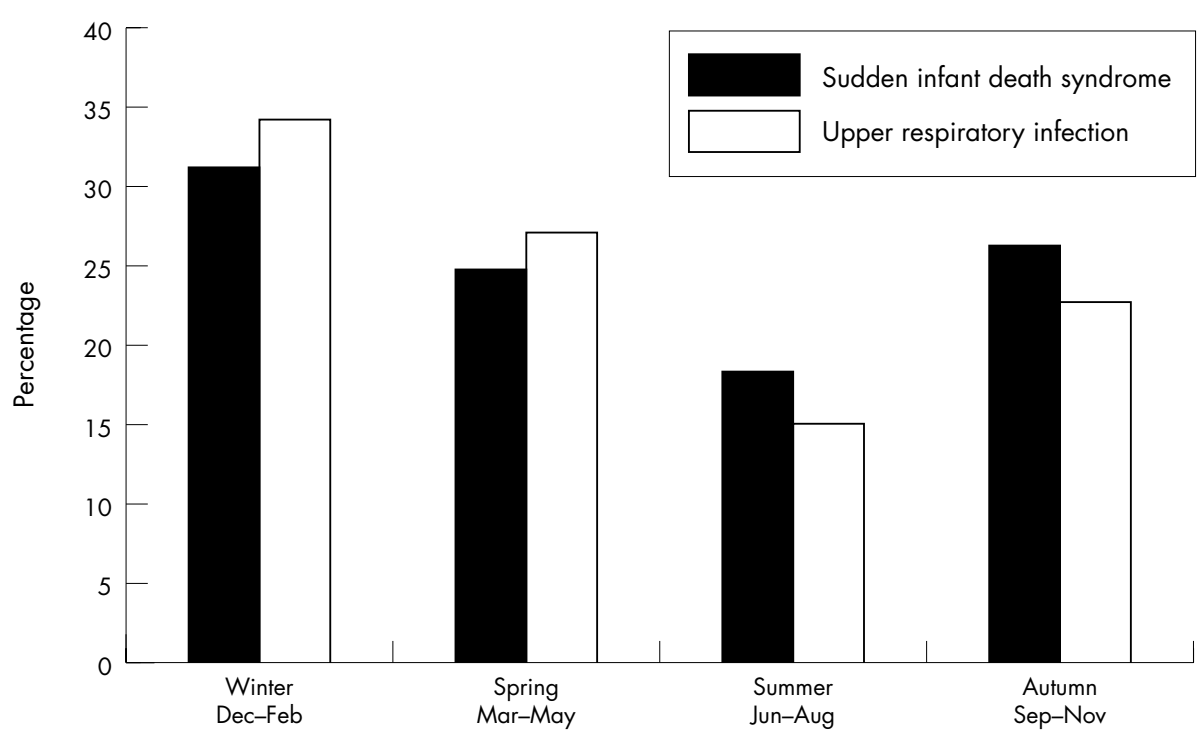

Figure 1 Seasonal distributions of SIDS and household URI in Hawaii, 1974-1982, showing winter maximums and summer minimums. ${ }^{13}$ 
Table 3 Increasing risk of SIDS with parity in the US 1995-1999, hypothesised to represent an infection vector from siblings during the school session ${ }^{25}$

\begin{tabular}{lll}
\hline $\begin{array}{l}\text { Live birth order } \\
\text { of a SIDS* }\end{array}$ & $\begin{array}{l}\text { Black infants- } \\
\text { SIDS/1000 }\end{array}$ & $\begin{array}{l}\text { White infants- } \\
\text { SIDS/1000 }\end{array}$ \\
\hline 1 & 0.91 & 0.51 \\
2 & 1.52 & 0.69 \\
3 & 1.78 & 0.75 \\
4 & 2.45 & 0.88 \\
5 & 2.80 & 1.05 \\
6 or more & 3.17 & 0.94 \\
\hline \multirow{2}{*}{ *Siblings may not all be alive or living at home. }
\end{tabular}

$S(\mathrm{~T} 2)-\mathrm{S}(\mathrm{T} 1)=$ the expected numbers of SIDS in the month.

An optimisation program was run to minimise the sum of the squared differences between the predicted numbers of monthly SIDS and the observed numbers shown in table 1. The two parameters of the model were found to be $A=296 /$ 384 and $\phi=30$ (30 January at $1159 \mathrm{pm}$ ), and $\mathrm{B}$ is determined by continuity as $1-A=88 / 384$. Equation 2 predicts 39.74 SIDS for January compared with the observation of 41, and the procedure is followed for the other 11 months. A Yates's $\chi^{2}$ statistic of the 12 predicted and observed monthly values was 8.02 with $9 \mathrm{df}$, for $\mathrm{p}=0.523$, so the cosine function of equation $\mathrm{l}$ is not rejected by this method as a reasonable description of the Hawaiian monthly SIDS data.

\section{DISCUSSION}

According to Samuels ${ }^{21}$ "Viral respiratory infections are the most likely trigger for sudden infant death syndrome (SIDS)." These viruses follow the seasonal pattern of SIDS with winter maximums and summer minimums. ${ }^{1422} 23$ Figure 1 shows this seasonal pattern for household upper respiratory infections (URI) in Hawaii, 1974-1982, ${ }^{13}$ which follows the pattern for respiratory syncytial virus in the US in the period 2000-2003..$^{24}$ The cosine function of equation 1 can be interpreted as 296 of the SIDS were not associated with a seasonally varying rate and 88 SIDS $(23 \%)$ were associated with the seasonally variable causes such as viral infection and paradoxical overheating during the colder months of the school session. Viral infections are often communicated to infants by their school age siblings. Table 3 shows the incidence of SIDS increasing with parity (number of live births) in the US for 1995 to $1999 .{ }^{25}$

East and Jacobsen ${ }^{26}$ report that the siblings (mean age 13.6 years) of parenting teens in their study spent 10 hours a week caring for their sisters' children. East and Kiernan ${ }^{27}$ report on a different cohort of 1510 predominantly Hispanic and black younger siblings of pregnant or parenting teens who had on average 1.8 brothers (range $0-10$ ) and 2.8 sisters (range 114).

These large family sizes suggest a large potential risk for the infant of a teen mother from infection via uncles and aunts of school age. Infants of unmarried mothers under 15 years and ages 15 to 19 years in the United States, 1995-1999, have the highest rates of SIDS (2.16/1000 and 1.56/1000 respectively) compared with any other age group, married or unmarried. ${ }^{25}$

Hawaii is a top tourist destination and the visitor influx represents a possible vector of new infection from Asia and the mainland United States. Summer is the peak period for tourist visits to Hawaii. For example, in 1999 in June to August there were 1.82 million visitors and in December to February there were 1.66 million visitors ${ }^{28}$ so the potential introduction of imported viruses would seem to be out of phase with SIDS and not likely to be responsible for the

\section{Key points}

Hawaii does not reach very low night time temperatures in the winter. Therefore the apparent cause for the annual winter maximum in Hawaiian SIDS may be a respiratory infection vector that is provided by close contact with school children.

seasonal effect. However, winter visitors may have a much higher rate of viral infection than summer visitors, although a Hawaiian infant would have less chance to have contact with a tourist than a parent, or an older sibling who may be in day care or school.

Alternative explanations for the universal winter peak of SIDS are effects from cold temperatures and higher air pollution caused by winter thermal inversions and excessive use of residential space heating that are not supported here because they do not present as possible causes in Hawaii, in part because almost all homes in Hawaii are not heated. The absence of indoor space heating during milder weather when night time temperatures decrease to $15^{\circ} \mathrm{C}$ may lead some parents to clothe their infant more than necessary leading to a paradoxical overheating. This is a known risk factor that can interact with the other risk factors of the prone sleep position and a respiratory infection. ${ }^{29}$ However, excess swaddling in the winter has not been observed in Honolulu SIDS cases (personal communication: Gwen Suzuki, MD, Office of the Medical Examiner, City and County of Honolulu, 2004). The prone sleep position is the central contributory cause of SIDS, but parents tend to use the same sleep position for their infants in all seasons, so a higher use of the prone position for sleep during the winter than the summer is not a likely cause of the seasonal difference. ${ }^{29}$

The seasonal pattern of SIDS in Hawaii where there is no large seasonal variation of temperature establishes that the global seasonal variations with maximum SIDS rates in winter and minimum SIDS rates in summer are not likely to be related to the effects of the outer air temperature itself or higher levels of air pollution commonly found during the winter. The school cycle may provide a seasonal infection vector to the SIDS infants from their siblings, if any, who are highly exposed to respiratory infections by the intimate contacts of the classroom and playground.

A myriad of other risk factors have been associated with SIDS, such as neurological prematurity, parental tobacco smoking, and a prone sleep position. ${ }^{30}$ Because these risk factors are all non-seasonal and gender independent they also cannot be the cause of either the seasonal relation or the $50 \%$ male excess. This suggests that a low grade respiratory infection (not sufficient to be diagnosed as the cause of death at necropsy) may be a contributory factor in the terminal process that leads to the seasonality of the SIDS.

\section{ACKNOWLEDGEMENTS}

Brian Horiuchi and Caryn Tottori of the Hawaii State Department of Health provided the monthly birth totals and the SIDS vital statistics for the years 1993-2002.

\section{Policy implications}

Hawaiian parents need to be educated to put their infants to sleep in the supine position, to recognise the symptoms of low grade respiratory infection in infancy, and not to over clothe their infants at night during cool evenings that seem cold in comparison with the normally semi-tropical weather. 
Funding: none

Conflicts of interest: none declared.

\section{REFERENCES}

1 Mage DT. A probability model for the age distribution of SIDS. Journal of Sudden Infant Death and Infant Mortality 1996;1:13-32.

2 Mage DT, Donner M. A genetic basis for the sudden infant death syndrome sex ratio. Med Hypotheses 1997;48:137-42.

3 Strimer R, Adelson L, Oseason R. Epidemiologic features of 1134 sudden unexpected infant deaths. JAMA 1969;209:1943-7.

4 Nelson EAS, Taylor BJ. Climatic and social associations with postneonatal mortality rates within New Zealand. N Z Med J 1988;101:443-6.

5 Beal SM. Some epidemiological facts about SIDS in South Australia. In: Tildon JT, Roeder LM, Steinschneider A, eds. Sudden infant death syndrome. New York: Academic Press, 1983:15-28.

6 Jones ME, Ponsonby AL, Dwyer T, et al. The relation between climatic temperature and sudden infant death syndrome differs among communities: results from an ecologic analysis. Epidemiology 1994;3:332-6.

7 Leiss JK, Suchindran CM. Sudden infant death syndrome and local meteorologic temperature in North Carolina. Am J Epidemiol 1996:144:111-15.

8 Little RE, Peterson DR. Sudden infant death syndrome epidemiology: a review and update. Epidemiol Rev 1990;12:241-6.

9 Hoppenbrouwers T, Calub M, Arakawa K, et al. Seasonal relationship of sudden infant death syndrome and environmental pollutants. Am J Epidemiol $1981 ; 113: 623-35$.

10 Woodruff TJ, Grillo J, Schoendorf KC. The relationship between selected causes of postneonatal infant mortality and particulate air pollution in the United States. Environ Health Perspect 1997; 105:608-12.

11 Lidwell OM, Sommerville T. Observations on the incidence and distribution of the common cold in a rural community during 1948 and 1949. J Hygiene 1951;49:365-9.

12 Dingle JH, Badger GF, Jordan WS. Illness in the home. A study. Cleveland: Western Reserve Press, 1964:80.

13 Seto DSY, Burch TA. The epidemiology of sudden infant death syndrome in Hawaii. R\&S report 50. Honolulu: Hawaii State Department of Health, 1984

14 Guntheroth WG, Lohmann R, Spiers PS. A seasonal association between SIDS deaths and kindergarten absences. Public Health Rep 1992;107:319-22.

15 Mage DT, Leiss JK, Takamori C. The epidemiology of SIDS in Hawaii: seasona variation in a state without seasons. In: Rognum TO, ed. Sudden infant death syndrome. New trends in the nineties. Oslo: Scandinavian University Press, 1995: 143-6.
16 NOAA Local climatologic data. Annual summary with comparative data: Honolulu International Airport. Ashville NC: National Climatic Data Center, 1992.

17 Edwards JH. The recognition and estimation of cyclic trends. Ann Hum Gene $1961 ; 25: 83-7$.

18 United States Department of Health and Human Services (US DHHS), Centers for Disease Control and Prevention (CDC), National Center for Health Statistics (NCHS), Office of Analysis and Epidemiology (OAE). Compressed mortality file (CMF) compiled from CMF 1968-88, series 20, no 2A 2003, CMF 1989-98, series 20, no 2E 2003 on CDC WONDER online database. (accessed 17 Aug 2003).

19 Willinger M, Hoffman HJ, Hartford RB. Infant sleep position and risk for sudden infant death syndrome: report of meeting held January 13 and 14 , 1994, National Institutes of Health, Bethesda, MD. Pediatrics 1994:93:814-19.

20 Takei N, O'Callaghan E, Sham P, et al. Seasonality of admissions in the psychoses: effect of diagnosis, sex, and age at onset. $\mathrm{Br} J$ Psychiatry 1992;161:506-11.

21 Samuels M. Viruses and sudden infant death. Paediatr Respir Rev 2003;4:178-83.

22 Howatt WJ, Moore IE, Judd M, et al. Pulmonary immunopathology of sudden infant death syndrome. Lancet 1994;343:1390-2.

23 Fleming KA. Viral respiratory infection and SIDS. J Clin Pathol 1992;45(suppl 11):29-32.

24 United States Department of Health and Human Services (US DHHS), Centers for Disease Control and Prevention (CDC), National Respiratory and Enteric Virus Surveillance System. http://www.cdc.gov/ncidod/dvrd/revb/nrevss/ trends.htm\#rsvgraph (accessed 25 Oct 2003).

25 United States Department of Health and Human Services (US DHHS), Centers for Disease Control and Prevention (CDC), National Center for Health Statistics (NCHS), Office of Analysis and Epidemiology (OAE). Linked birth and death file (LBDF), computer tape, CDC WONDER online database (accessed 17 Aug 2003).

26 East PL, Jacobson $\amalg$. The younger siblings of teenage mothers: a follow-up of their pregnancy risk. Dev Psychol 2001;37:254-64.

27 East PL, Kiernan EA. Risks among youths who have multiple sisters who were adolescent parents. Fam Plann Perspect 2001;33:75-80.

28 Hawaiian Visitors Bureau. http://www.state.hi.us/dbedt/monthly/ index99.html (accessed 19 Aug 2003).

29 Ponsonby AL, Dwyer T, Gibbons LE, et al. Factors potentiating the risk of sudden infant death syndrome associated with the prone position. NEngl J Med 1993:329:377-82.

30 Guntheroth WG. Crib death: the sudden infant death syndrome. 3rd ed. Armonk: Futura, 1995:125, 220-1, 268. 